\title{
PEOPLE OF SALE
}

\$n1e;1

harv;45301;r;n

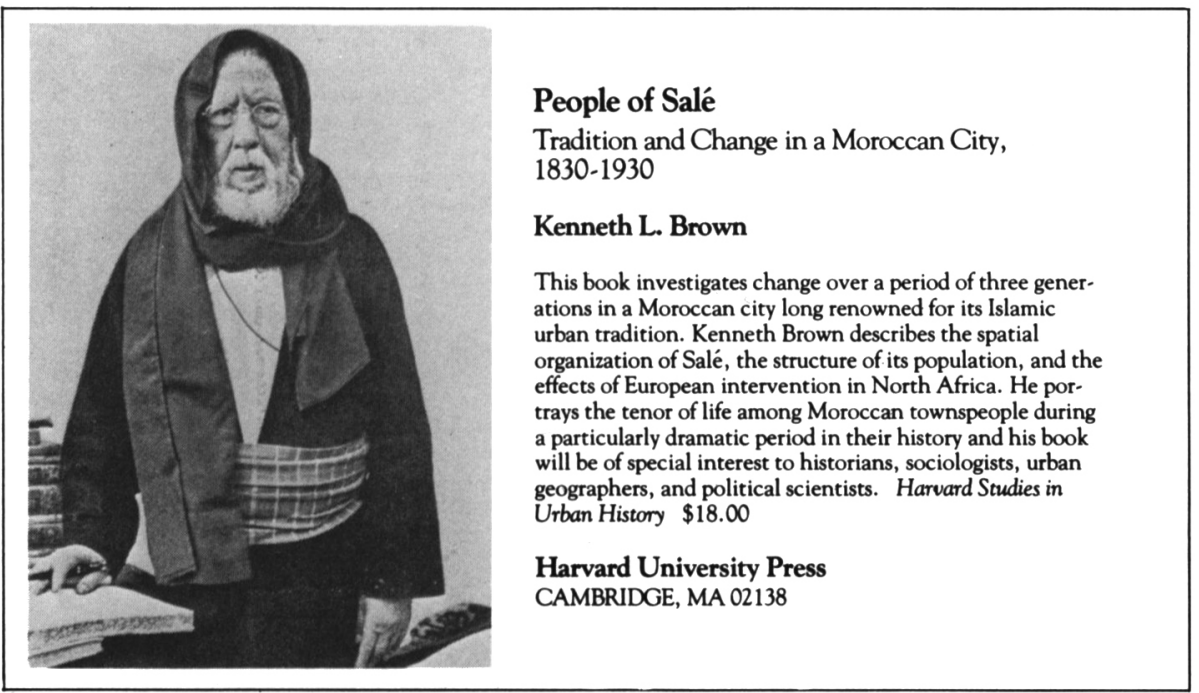

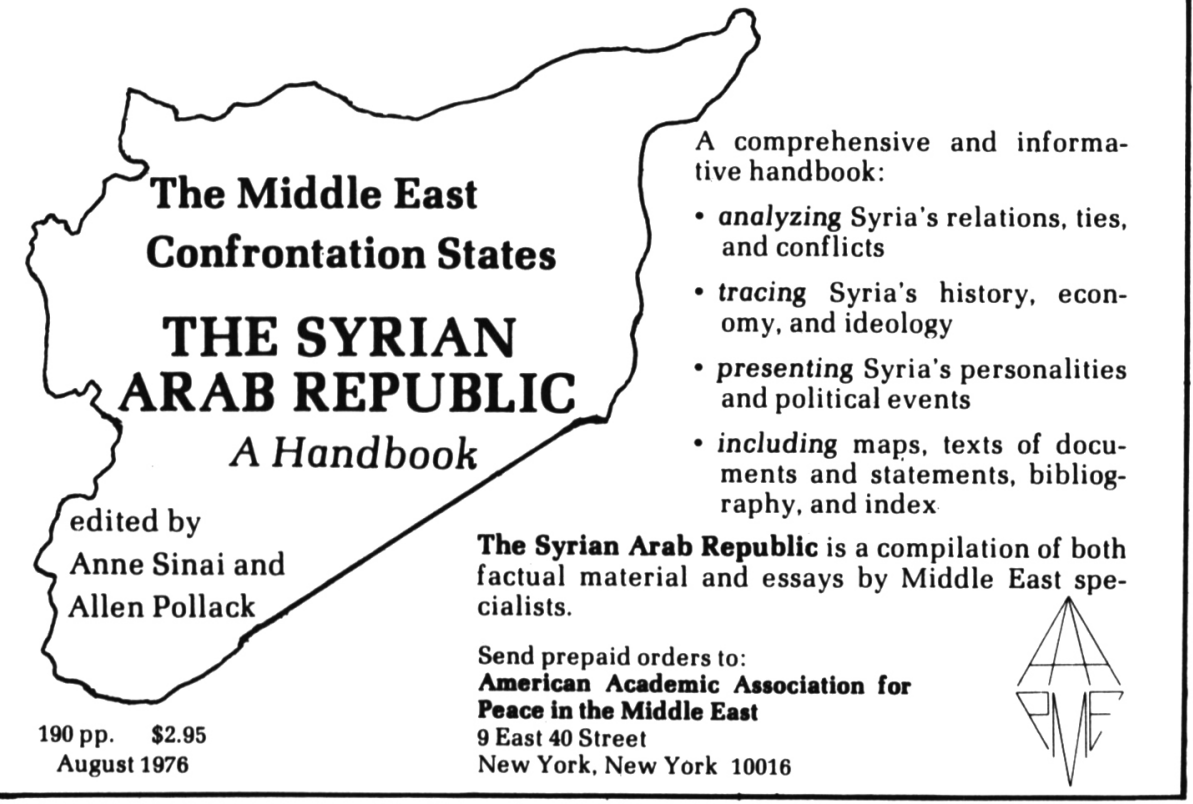




\title{
Crossroads to Civil War: Lebanon 1958-1976
}

\author{
by KAMAL S. SALIBI \\ Professor of History; A merican University of Beirut
}

On 13 April 1975, an eruption of violence in the suburbs of Beirut between Christian Lebanese militiamen and Palestinian commandos unleashed a series of armed confrontations and clashes which continued to rage in Lebanon as this book went to press. At one level, the clashes took the form of a civil war among the Lebanese themselves who, as Christians and Muslims, or as conservatives and radicals, have been in serious disagreement over a number of domestic and regional issues for nearly two decades. At another level, the violence involved hostilities between the Christian Lebanese and the Palestinians who have been refugees in Lebanon since the emergence of Israel in 1948 on the territory of what was formerly British-mandated Palestine. At yet another level, the armed conflict in Lebanon between Christians and Muslims, conservatives and radicals, Lebanese and Palestinians, was inextricably connected internally with social pressures resulting from rapid urbanization, and externally with the issue of the Middle Eastern settlement between the Arab States and Israel.

On the subject of the Lebanese civil war, few can write with the authority of Professor Kamal S. Salibi who is already well-known to Western readers on the Middle East for his studies on Lebanese history and politics. In this book, Professor Salibi reviews the complex structural dynamics of the conflict in Lebanon in the form of a historical narrative starting from the Muslim-Christian Lebanese confrontation of 1958. For anyone interested in gaining insight into the Lebanese situation in its full domestic and regional context, Crossroads to Civil War, which is both a study and a document, is indispensable reading.

\section{CARAVAN BOOKS Box 344, Delmar, N.Y. 12054}

